
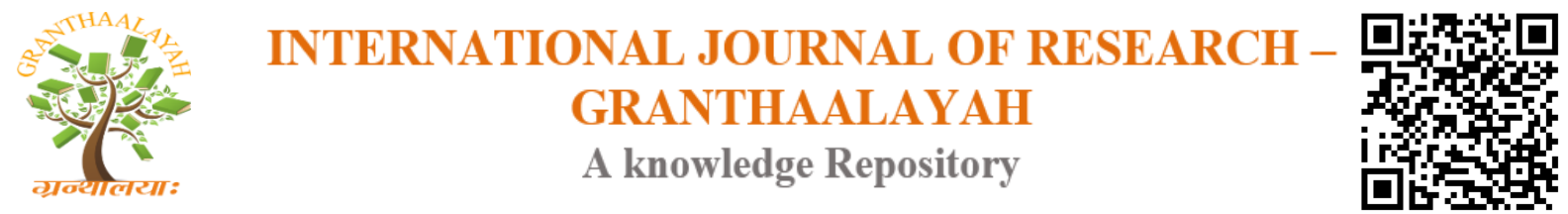

Science

\title{
THE EFFECT OF CEMENT ADDITIVES IN PVC MATERIALS
}

\author{
Kitti Ungai *1 \\ ${ }^{* 1}$ University of Agriculture, Department of Export, Hungary
}

\begin{abstract}
The aim of the present paper is to show the effect of cement modifier behaviors in PVC materials. The PVC and the Portland cement are important materials in the industrial area. It can reach excellent properties if mixing the two materials with each other. The cement worked as filler in PVC, as shown the mechanical tests. The oxygen index was determined, accordingly the result show higher oxygen index value. That means the blend shows higher fire resistance comparing to neat PVC. The cement worked as a structural modifier, it caused modification in the blends structure and properties. From the mechanical tests, such as impact-, tensile-, flexuraland hardness tests the blend gives similar mechanical properties to neat PVC. The research presented in this paper shows that the cement mixed with PVC shows higher stability, fire resistance and similar mechanical properties as rigid PVC.
\end{abstract}

Keywords: Cement; Mechanical Properties; Oxygen Index; PVC/Cement Blends.

Cite This Article: Kitti Ungai. (2017). "THE EFFECT OF CEMENT ADDITIVES IN PVC MATERIALS." International Journal of Research - Granthaalayah, 5(11), 206-209. https://doi.org/10.29121/granthaalayah.v5.i11.2017.2348.

\section{Introduction}

Studies have pointed out the polymer additives strengthening effect with cement based materials. In case we examined the cement additives modifier properties to the PVC based materials. The PVC [poly (vinyl-chloride) is a worldwide used materials, which can be found at every industrials area. Out of PVC materials industry produces a wide variety of products, such as pipes, insulators, foams, coatings ${ }^{[1]}$. In the recent decade, the mechanism of polymer modified cement was known. The polymer modified cement is widely used in external wall insulation, bridges due to their higher strength and workability properties ${ }^{[2]}$. Some earlier study adds information about the polymer-cement complex's unsatisfactory capabilities. Nowadays, new method was the latex mixing with other polymers, such as neoprene emulsion (CR latex) or polyvinyl chloride-vinylidene chloride emulsion (PVDC latex). The reason for that was the excellent tough and water reduction properties of the cement blend. These composites have been already used as the adhesive layer, finishing materials or reinforced structures. Based on the previous researches, the chemical modification of the cement improves adhesion, flexural strength and crack resistance of the cement ${ }^{[3]}$. 


\section{Materials and Methods}

\subsection{Materials}

The basic material was the PVC; the additive was the Portland cement. The production needs some processing additives, such as processing aids, fillers, stabilizer (mostly used $\mathrm{Ca}-\mathrm{Zn}$ ), and other additives, which improves higher thermal properties, stability and fire resistance. We experimented with many PVC/cement ratio, these was 0.1 to $25 \mathrm{wt} \%$, with different size of cement (micron- and nanometer) components. This paper presents only the 100/10 wt\% $\mathrm{PVC} /$ cement ratio.

The base cement includes $75-80 \mathrm{~m} \%$ limestone and $20-25 \mathrm{~m} \%$ other materials ${ }^{[4]}$. It was an excellent additive to PVC, because in the PVC industry the limestone was used in fillers. The blend's density value was $1.4438 \mathrm{~g} / \mathrm{cm}^{3}$, and the oxygen index 49 . If the oxygen index is greater than 22 the materials has self-extinguishing property.

\subsection{Sample Preparation}

The commercial cement was pure powder. Own formulation was produced by mixing component with fluid mixer, after that extrusion at $180^{\circ} \mathrm{C}$ into sheets of $1 \mathrm{~mm}$ in thickness. The specimens were produced directly from the extruded sheets. Specimens were die-cut for all the measurements by INTESZT die puncher. Several test was performed on the PVC/cement blend, such as tensile-, impact-, bending-, hardness test.

\subsection{Hardness Test}

During the test there was a measure of the penetration of inventor into the materials. Usually, this type of measurements (Shore D) is used to examine the hardness values of plastics, elastomers and engineering plastics ${ }^{[5]}$. The measurement was carried out according to ISO 868 standard at room temperature ${ }^{[6]}$. The test was executed with Zwick/Roell (bench-top) equipment. The average values of 50 measurements can be determined.

\subsection{Tensile Test}

The test was carried out with INSTRON 5900 equipment. It was made at room temperature $(23 \pm 1)$ with $50 \mathrm{~mm} / \mathrm{min}$ speed. The data from the method was used to determine the material properties such as strength-strain values, modulus or yield strength ${ }^{[7]}$. The test was performed according to ASTM D368-10 ${ }^{[8]}$.

\subsection{Impact Test}

The impact test was carried out with Atestor equipment, according to EN ISO $179{ }^{[9]}$. With the measurements the materials maximum impact bending strength can be determined. The specimen was in $0.2 \mathrm{~mm}$ radius of notches. The equipment's has hammer of $4 \mathrm{~J}$. 


\subsection{Flexural Test}

The test provided the graph of load versus displacement. Measurements were carried out with a similar machine to the tensile test, it was INSTRON 5900. During the method three points bending head was used. The test was according to ISO 178:2010 ${ }^{[6]}$.

\section{Results and Discussions}

Table 1: Results of the all mechanical tests

\begin{tabular}{|l|l|l|}
\hline Test methods & Origin PVC & PVC/cement blend \\
\hline Hardness test (average value) & $73.94 \pm 0.66$ & $76.01 \pm 0.61$ \\
\hline Maximum Tensile Strength [MPa] & $53.09 \pm 1.4$ & $53.21 \pm 0.4$ \\
\hline Impact strength [kJ/m2] & $2.15 \pm 0.13$ & $1.79 \pm 0.09$ \\
\hline Flexural strength [MPa] & $135.9 \pm 2.3$ & $124.1 \pm 2.6$ \\
\hline Flexural modulus [MPa] & $8317.8 \pm 182.3$ & $7798.6 \pm 72.7$ \\
\hline & & \\
\hline
\end{tabular}

Figure 1: Original and blend tensile stress-strain curves

Figure 1 shows the tensile stress- elongation values. Generally, the original has longer extension values, but the tensile strength properties are similar. The ultimate yield of blend was smaller, that means the original PVC has greater lifetime with higher stress. The results of the maximum values were show in Table 1.

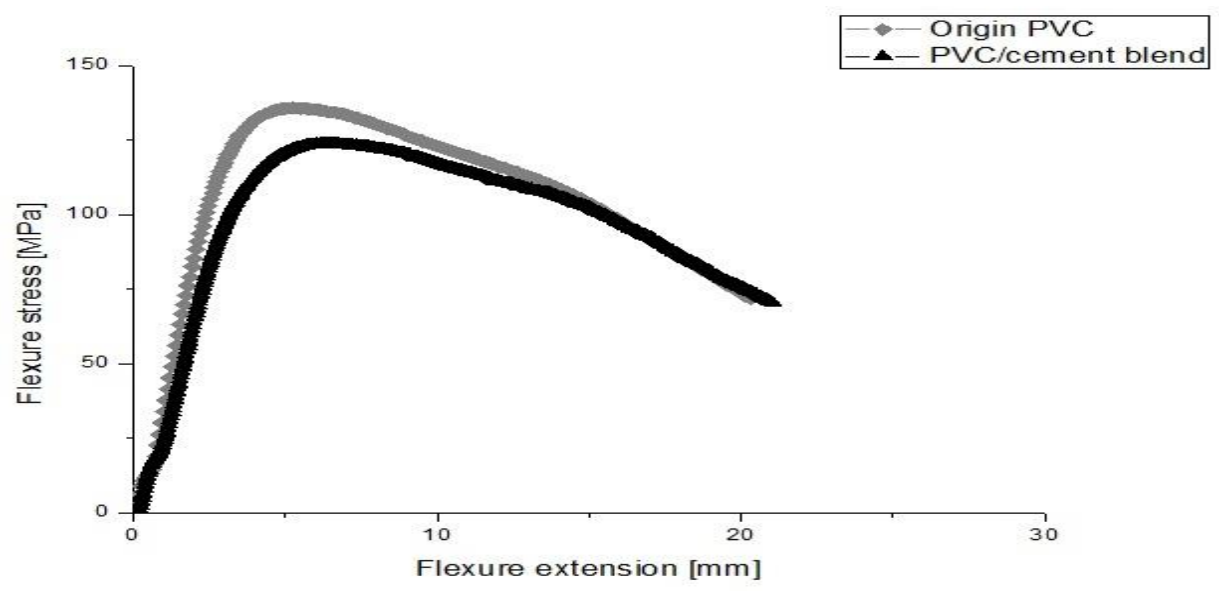

Figure 2: Results of origin and blend flexural test 
The flexural test showed only a slight change in the flexure strength. The Table 1. contains the results of the maximum flexure stress measurement.

The dynamic maximum strength of blends can be examined. The cement was strengthened the exterior of the material. Even so the neat sample has greater impact properties, accordingly at Table 1.

The hardness test shows, that the cement significantly solidified the external structure, but the properties of mixtures did not change greatly.

\section{Conclusions}

PVC and cement additive sheets were prepared by extrusion. The cements main component was the $\mathrm{CaCO}_{3}$, so it worked as filler in the PVC base materials. Mechanical and oxygen index values measurements were carried out on neat and blend samples. The blend showed less strength by high deformation mechanical test. In the tensile strength values there could not be seen higher modification. The original PVC provided better strength according to flexural- and impact tests. There is a change in the hardness value, because of cement, which hardened the blend matrix and structure. All in all the cement was an excellent additive to PVC, because the commercial price/value ratio is appropriate. It is also necessary to examine the internal properties of the blends. The internal structure will give some information about the additives function; according to it, structures stability may increase.

\section{References}

[1] W.V.Titow: PVC Technology; Fourth Edition, England, Elsevier Applied Science Publishers 1984.

[2] Min Wang, Rumin Wang, Hao Yao, Shameel Farhan, Shuirong Zheng, Zhujun Wang, Congcong Du, Hao Jiang: Research on the mechnicm of polymer latex modified cement, Construction and Building Materials, 2016, 710-718.

[3] Omid Akhlaghi, Tunahan Aytaas, Buse Tatli, Dilek Sezer, Amin Hodaei, Aurélie Favier, Karen Scrivener, Yusuf Z. Menceloglu, Ozge Akbulut: Modified poly(carboxylte ether)-based superplasticizer for enhanced flowability of calcined clay-limestone-gypsum blended Portland cement.

[4] Dr. Német Béla: Industrial technologies, 2013, University of Pecs,

[5] MatWeb: Material property data, http://www.matweb.com/reference/shore-hardness.aspx

[6] ISO: International Organization for Standardization https://www.iso.org/home.html

[7] Stephan Favilla: Tensile Testing Laboratory Report, 11. 02. 2010

[8] Instron, STM D638-14 Tensile Properties of Plastics http://www.instron.co.hu/hu-hu/testingsolutions/by-test-type/tension/ASTM-D638-10 properties.

\footnotetext{
*Corresponding author.

E-mail address: ungaikitti@ freemail.hu
} 